\title{
Editorial
}

\section{Cholesterol embolisation}

The clinical consequences of cholesterol embolisation vary considerably. Patients may be completely asymptomatic when the diagnosis is made coincidentally at renal biopsy or they may present with a distinct clinical syndrome that is associated with a high mortality. As only a minority of patients sustaining cholesterol emboli are recognised clinically, the actual incidence and pathophysiology of the syndrome remains uncertain.

Typical features of the clinical syndrome include livedo reticularis and painful focal digital ischaemia, characteristically with a normal peripheral arterial pulse (the purple toe syndrome). Other clinical features include retinal embolisation, renal failure (usually with baseline renal impairment), labile blood pressure, and abdominal symptoms that may vary depending on which organ is involved.

Tissue biopsy is the diagnostic investigation of choice. Skin or muscle biopsy can be used but where possible the affected organ should be biopsied. The characteristic pathological lesion is occlusion of affected arterioles by luminal needle shaped cholesterol clefts (fig 1). The kidney is the solid organ most commonly affected and renal biopsy is abnormal in approximately $70 \%$ of patients with the cholesterol emboli syndrome.

Making a clinical diagnosis of cholesterol embolisation requires a high index of suspicion as there is no diagnostic serological investigation, and differentiation from a systemic vasculitis can be difficult. ${ }^{2}$ Abnormalities of routine investigations are generally non-specific, but include an acute phase response (elevated $\mathrm{C}$ reactive protein, normochromic normocytic anaemia, and leucocytosis), a transient eosinophilia, thrombocytopenia, reduced complement levels, proteinuria or haematuria or both.

Cholesterol embolisation may be spontaneous or it may occur within eight weeks of arteriography, angioplasty, cardiac surgery or thrombolysis. Elderly male smokers with a history of hypertension and vascular disease appear to be at particular risk. Penetrating mobile semi-occlusive atheroma of the aorta detected by transoesophageal echocardiography has been demonstrated in a number of cases (fig 2). ${ }^{3}{ }^{4}$ This pattern of atheroma is an unusual finding and it appears to be a marker of severe widespread atheromatous disease. Further studies into the relation

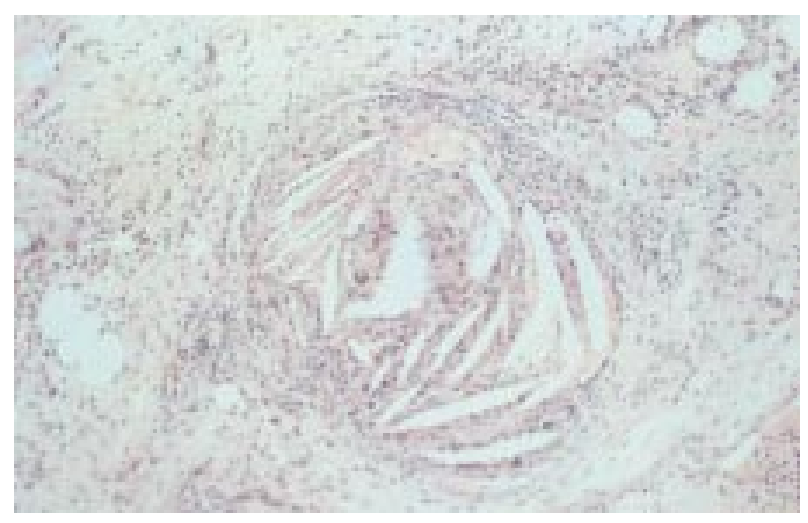

Figure 1 Cholesterol clefts within an arteriole from resected colon in a patient with the cholesterol emboli syndrome.
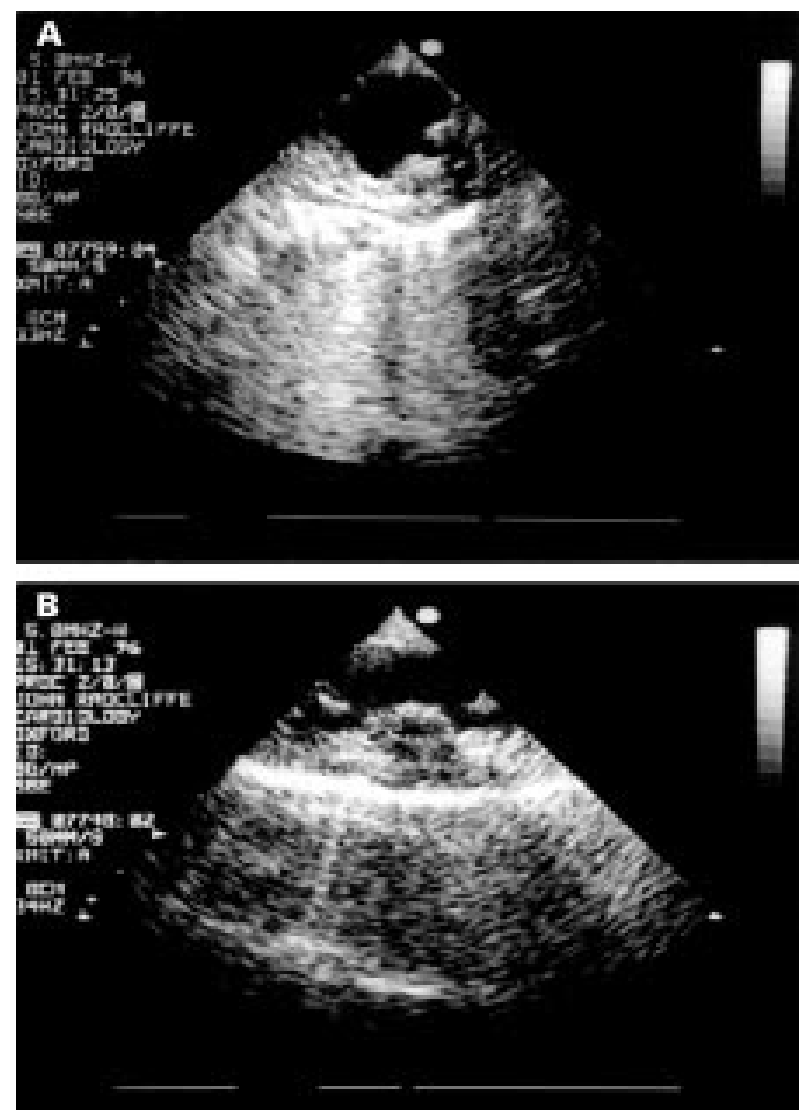

Figure 2 Transverse cross sectional transoesophageal echocardiography scan of the upper descending aorta $(A)$ demonstrating mobile protruding atheroma. In the longitudinal plane (B) the extent of luminal encroachment with calcification is apparent.

between this pattern of atheromatous aortic disease and the cholesterol emboli syndrome are currently in progress.

The outcome of patients with cholesterol embolisation varies considerably. In patients undergoing investigation and treatment for ischaemic heart disease, muscle biopsy has demonstrated cholesterol clefts in $10 \%$ of patients. ${ }^{5}$ None of these patients had any clinical sequelae. In contrast, the clinical syndrome of cholesterol embolisation has a poor prognosis particularly when there is evidence of visceral and renal involvement. Mortality in these patients may approach $80 \%$.

Conventional treatment is supportive with aggressive blood pressure control and, if necessary, renal replacement treatment. There is no evidence that steroids ${ }^{1}$ or anticoagulation $^{6}$ are beneficial. Some centres have advocated arterial surgery for atheroembolic disease, however, there are no randomised comparisons of surgery with medical treatment. In patients who are gravely ill, the extent of the vascular disease and the presence of multiorgan involvement makes any proposed surgical intervention extremely high risk.

\section{Conclusions}

The incidence of cholesterol embolisation is probably underestimated as it may be clinically silent. When the 
clinical syndrome does occur, it is difficult to diagnose. Patients with diffuse vascular disease who have undergone a recent vascular intervention are at particular risk. An increased awareness of the diagnosis and further research into the pathophysiological mechanisms underlying cholesterol embolisation are necessary to improve understanding and reduce patient mortality.

ADRIAN P BANNING WILLIAM P ORR

Department of Cardiology, BRIAN GRIBBIN
1 Fine MJ, Kapoor W, Flanga V. Cholesterol crystal embolization: a review of 221 cases in English Literature. Angiology 1987;38:769-84.

2 Peat DS, Mathieson PW. Cholesterol emboli may mimic systemic vasculitis. BMF 1996;313:546-7.

3 Grentzinger A, Juilliere Y, Anconina J, Buffet P, Giorgi JP, Nizak J, et al. Systemic embolism and aortic atheroma. Contribution of transoesophageal echography. Apropos of a case of systemic embolism caused by cholesterol crystals. Ann Cardiol Angeiol 1994;43:14-16.

4 Sato Y, Takei H, Katsumata N, Matsumoto N, Akiyama H, Narumiya T, et al. Transesophageal echocardiographically detected atherosclerotic aortic debris in a patient with systemic embolism following coronary angiography. Heart Vessels 1995;10:167-9.

5 Blankenship JC, Butler M, Garbes A. Prospective assessment of cholesterol embolization in patients with acute myocardial infarction treated with thrombolytic vs conservative therapy. Chest 1995;107:662-8.

6 Burns FJ, Segel DP, Adler S. Control of cholesterol embolization by discontinuation of anticoagulant therapy. Am f Med Sci 1978;275:105-8

\section{The electrocardiogram on stamps (part 2)}

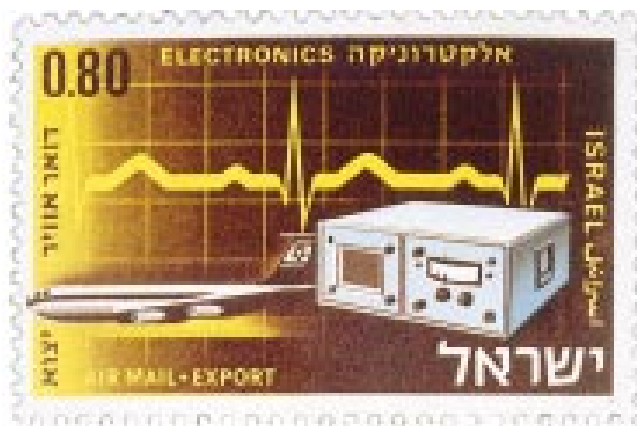

The theme for the World Health Day in 1992 was "Heart beat - the rhythm of health" resulting in the appearance of a few additional stamps featuring the electrocardiogram in their design as well as the heart. The stamps from Zambia and Iran issued for this health campaign are shown. The Iranian stamp is interesting in so far as the electrocardiogram shows ventricular bigeminy whereas, usually, normal electrocardiograms are included in the design. One of the few stamps that contains an electrocardiogram separate from a health or cardiac theme came from Israel in 1968. The 80 agorot stamp is part of a 10 stamp airmail set issued depicting Israeli exports, and features telecommunications equipment and electronics. The other stamps in the set include textiles, fruit, and flowers.
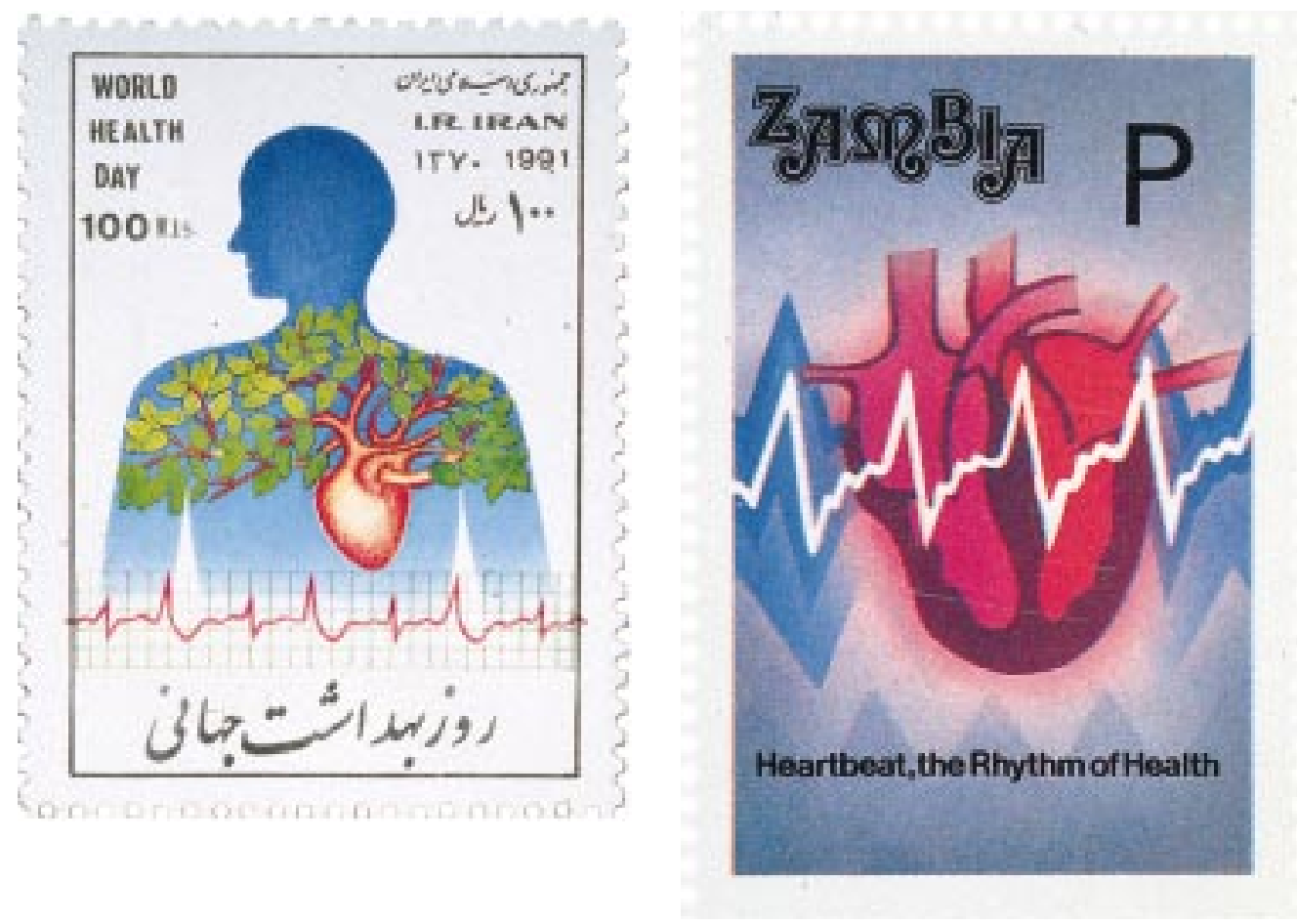